\title{
The Role of Pain Catastrophizing in the Prediction of Acute and Chronic Postoperative Pain
}

\author{
Ran Kremer ${ }^{1}$, Michal Granot ${ }^{2, *}$, David Yarnitsky ${ }^{3}$, Yonathan Crispel $^{3}$, Shiri Fadel ${ }^{3}$, \\ Lael Anson Best ${ }^{1}$ and Rony-Reuven $\mathrm{Nir}^{3}$
}

\author{
${ }^{I}$ Department of General Thoracic Surgery, Rambam Health Care Campus, and Faculty of Medicine, Technion - Israel \\ Institute of Technology, Haifa, Israel; ${ }^{2}$ Faculty of Welfare and Health Sciences, University of Haifa, Haifa, Israel; \\ ${ }^{3}$ Department of Neurology, Rambam Health Care Campus, and Laboratory of Clinical Neurophysiology, Faculty of \\ Medicine, Technion - Israel Institute of Technology, Haifa, Israel
}

\begin{abstract}
Background and Objectives: Despite the established association between greater pain catastrophizing and enhanced postoperative pain, it is still unclear: (i) what is the relative contribution of each of the pain catastrophizing scale (PCS) dimensions in the prediction of acute and chronic postoperative pain; and (ii) whether PCS scores mediate the association between acute and chronic postoperative pain intensity.

Methods: The current prospective, observational study was conducted at Rambam Health Care Campus, Haifa, Israel. PCS was obtained in 48 pain-free patients a day before an elective thoracotomy in response to tonic heat pain. Acute postthoracotomy pain (APTP) was assessed during rest, including general pain (Rest general $_{\text {) }}$, and incision-related pain (Rest $\left.{ }_{\text {incision}}\right)$, and in response to provoked physical activity, including hand elevation (Provoked $\left.{ }_{\text {hand }}\right)$ and cough (Provokedcough). Chronic postthoracotomy pain (CPTP) was assessed after $4.5 \pm 2.3$ months.

Results: Of the PCS subscales, only rumination: (i) was correlated with Rest $t_{\text {general }}$ scores ( $\left.\mathrm{r}=0.337, P=0.027\right)$; and (ii) predicted chronic postthoracotomy pain in a regression analysis $(P=0.001)$. General PCS and its subscales mediated the correlation between Rest $_{\text {general }}$ and chronic postthoracotomy pain intensity $\left(P_{\mathbf{S}}<0.006\right)$.

Conclusions: Findings may elucidate the unique role of the rumination subscale in reflecting an individual's postoperative acute and chronic pain responsiveness. The transition from acute to chronic postoperative pain seems to be facilitated by enhanced pain catastrophizing.
\end{abstract}

Keywords: Pain catastrophizing, postoperative pain, acute postoperative pain, chronic postoperative pain, mediation analysis.

\section{INTRODUCTION}

Various factors have been indicated as potential predictors of individual pain experiences, including attentional and emotional processes, avoidance behavior, hypervigilance, and pain-related anxiety and catastrophizing [1-4]. Of these, pain catastrophizing has been broadly conceived as an exaggerated negative "mental set" brought to bear during an actual or anticipated pain experience and has risen to the status of one of the most important psychological predictors of pain $[1,5,6]$. In keeping, enhanced scores of pain catastrophizing were found to characterize patients who suffer from various chronic pain disorders, such as temporomandibular muscle and joint disorders [7] as well as endometriosis [8], fibromyalgia, [4] and headache [9].

While the association between postoperative pain reports during the acute and chronic phases and pain catastrophizing levels has been established [3,10-13], it is still unclear

*Address correspondence to this author at the Faculty of Welfare and Health Sciences, University of Haifa, Mount Carmel, Haifa 31905, Israel; Tel: + 9724828 8006; Fax: + 9724828 8017;

E-mail: granot@research.haifa.ac.il whether individual predisposition towards enhanced pain catastrophizing directly shapes and determines pain manifestation in the clinical setting or indirectly affects pain experiences. Furthermore, it has not been fully revealed whether pain catastrophizing directly affects the intensity of acute and chronic postoperative pain, or indirectly mediates the transition of the former to the latter.

Relevant literature addressed the valuable contribution of pain catastrophizing to the prediction of postoperative pain, during the acute phase, [14-16] including total knee replacement [15] and lumbar fusion surgery [17], as well as the chronic phase, [18, 19]. Conversely, several studies reported no association between pain catastrophizing and the experiences of postoperative pain [11]. This discrepancy emphasizes the need to further explore the role of presurgically obtained pain catastrophizing scores in the prediction of postoperative pain. Specifically, whether pain catastrophizing directly leads to greater chronic postoperative pain, or is indirectly involved in the transition from acute into chronic pain, has not yet been revealed. The characteristics of such association are affected by the condition in which the postoperative pain is assessed, namely rest or activity. The former includes spontaneous 
postoperative pain relating to either the incision area or the entire body, while the latter comprises provoked pain stimulated by somatic and/or visceral nociceptive activity. Such an elaborate set of measures of postoperative pain intensity is to be included in an investigation aimed at elucidating whether pain catastrophizing interacts with or mediates chronic postoperative pain. According to Sullivan et al. [1], the pain catastrophizing scale (PCS) contains three distinguished subscales: rumination, magnification, and helplessness. It may be assumed that a specific subscale reflects subjective pain experiences to a greater extent compared to the others.

The goal of the current study was to address the role of each PCS subscale in each of the postoperative pain measures during the acute and chronic postoperative phases. Thoracotomy is known as a surgery that induces a great deal of acute postoperative pain, and is associated with a high incidence of chronic postoperative pain. Thus, the current study enrolled thoracotomy patients in whom the level of clinical pain was obtained during the acute and chronic postoperative phases in order to reveal (i) the relative contribution of each of the PCS subscales to postoperative pain experiences; and (ii) whether the association is direct or indirect.

\section{MATERIALS AND METHODOLOGY}

\section{Patient Population}

Participants were pain-free patients, with both malignant and non-malignant diseases, who were scheduled to undergo major elective thoracic surgery at Rambam Health Care Campus, Haifa, Israel, during the time period of 2007 to 2008. All patients were informed of the study procedure and signed a written informed consent. The study was approved by the Rambam Health Care Campus Research Ethics Board (Approval RBM2036). Exclusion criteria were: 1) Presence of thoracic pain; 2) Consumption of analgesics on a regular basis; 3) Psychiatric disorders or cognitive dysfunctions; and 4) Ages below 18 and above 80 years. Data were collected by the same experimenter (SF).

\section{Assessment of Pain Catastrophizing Levels}

Pain catastrophizing was prospectively assessed one day before the surgery by the PCS [1]. This questionnaire includes 13 items representing the three components of pain catastrophizing: rumination (e.g., "I can't seem to keep it out of my mind"); magnification (e.g., "I wonder whether something serious may happen"); and helplessness (e.g., "There is nothing I can do to reduce the intensity of pain"). This scale has been validated in Hebrew [12]. The questionnaire was completed in relation to an experimental pain stimulation induced by tonic contact-heat.

\section{Contact-Heat Stimulation}

The experimental pain stimulation was of $46^{\circ} \mathrm{C}$, and was applied for 30 seconds by a contact-heat Thermal Sensory Analyzer 2001 system (TSA; Medoc, Ramat-Yishai, Israel) with a $30 \times 30 \mathrm{~mm}$ Peltier surface stimulator. The probe was attached by Velcro straps to the volar surface of the forearm of the subjects' non-dominant hand; this enabled the application of constant pressure throughout the stimulation and minimized the variability of the applied pressure across subjects.

\section{Surgical Procedure}

All patients underwent a thoracotomy operation by the same thoracic surgeon (RK), based on the Limited ribs spreading lateral thoracotomy procedure. This procedure was applied to attenuate pain during the immediate and longterm postoperative phases. All patients underwent such procedure in which lateral thoracotomy was conducted while sparing the serratus muscle and avoiding rib fracture. Special attention was given to minimizing rib spreading, which was limited to $10 \mathrm{~cm}$. Compared to the standard thoracotomy procedure, gradual ribs expansion was applied by using a smaller rib-spreader at the beginning, which was replaced subsequently by the usual rib-spreader. Special attention was given to the level of mechanical strength of the pericostal fixation. In order to avoid unintentional unseen rib fractures, the intercostal muscle incision was extended in order to allow better chest-wall compliance. As to the chest wall closure procedure, the technique was modified from the continuous non-absorbable pericostal sutures (prolane) to absorbable interrupted sutures (vycril).

All surgeries were performed under general anaesthesia using double lumen endotracheal intubation, in addition to regional anaesthesia with continuous thoracic epidural catheter using local anaesthetics and opioids. The same experienced team of anaesthetists was in charge of the epidural catheterization. Time of surgery was approximately 100 minutes (skin to skin).

\section{Postthoracotomy Pain Management}

All patients were treated with the routine acute postthoracotomy pain management protocol, consisting of epidural analgesia for the first three days after surgery (continuous infusion of $6 \mathrm{ml} /$ hour bupivacaine $0.125 \%$ (144 $\mathrm{ml} /$ day $)$ with fentanyl $2 \mu \mathrm{g} / \mathrm{ml}(288 \mu \mathrm{g} / \mathrm{d}))$ and supplemented by oral medications, including opioid analgesics (morphine up to $10 \mathrm{mg} / \mathrm{d} \times 3 /$ day $(30 \mathrm{mg} /$ day $)$, tramadex $100 \mathrm{mg} / \mathrm{d} \times$ 3/day (300 mg/day), Voltaren $75 \mathrm{mg} / \mathrm{d} \times 3 /$ day $(225$ $\mathrm{mg} /$ day)), according to each patient's requirement. Two patients had their epidural stopped, due to systemic itching unrelated to analgesic effectiveness. After removal of the epidural catheter, patients received oral analgesics as detailed above according to requirement. The individual opioid consumption, requested in addition to the epidural analgesia, was calculated daily during the first six postthoracotomy hospitalization days.

\section{Assessment of Acute and Chronic Postthoracotomy Pain Intensity}

Postthoracotomy pain intensity was reported using a 0 100 Numerical Pain Score (NPS) in which 0 represented "no pain" and 100 corresponded to "the worst pain imaginable". The assessment of acute postthoracotomy pain (APTP) was performed during two different conditions: (1) spontaneous pain at rest, and (2) in response to provoked physical activity. The first condition included two aspects, namely the

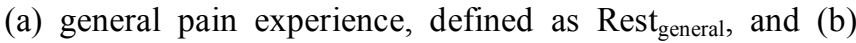

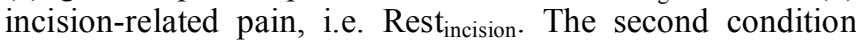
also included two aspects, which were induced by instructed 
physical activities, guided by the study experimenter (SF): (a) hand elevation ipsilateral to surgery site, defined as Provoked $_{\text {hand }}$ and (b) cough, defined as Provoked cough. $_{\text {. }}$ Assessments of APTP intensities were performed during morning hours in order to minimize the variation in pain scores. APTP scores were assessed twice along the period of hospitalization, once during the second day (at least 24 hours after the completion of surgery, while all patients received epidural analgesia) and again during the fifth day postthoracotomy (at least 24 hours after removal of the epidural catheter).

Follow-up for chronic pain (CPTP) was conducted at least 3 months postthoracotomy. Patients were asked during their follow-up visits in the postthoracotomy outpatient clinic to report the average pain intensity experienced in the area of the thoracotomy-induced scar during the last week. CPTP intensity $\geq 30$ defined chronic pain patients.

\section{Statistical Analysis}

Statistical analyses were conducted using SPSS 19 (SPSS Inc., Chicago, IL, USA). The outcome measures were the means of Rest general, Rest $_{\text {incision, }}$ Provoked ${ }_{\text {hand }}$, Provoked pough $_{\text {}}$ and CPTP intensities. Differences between the CPTP and non-CPTP patients were examined by unpaired two-tailed $t$ tests. Associations between pain catastrophizing level, age, and APTP as well as CPTP intensities were examined by Pearson correlations. Sobel mediation analysis examined whether the transition from acute to chronic pain was mediated by PCS scores. Linear regression analysis was conducted to explore the effect of pain catastrophizing level, age, and gender on the intensity of postthoracotomy pain. Statistical significance was set at $P<0.05$.

\section{RESULTS}

\section{Descriptive Statistics}

Data analysis consisted of 48 postthoracotomy patients, of whom 17 were females $(35.4 \%)$ and 31 were males $(64.6 \%)$. A total of 46 patients were available for both acute and chronic postthoracotomy pain assessments. Mean age and education years were $61.90 \pm 11.44$ and $12.54 \pm 4.30$, respectively. Table 1 presents the scores of the total PCS questionnaire as well as its three subscales. No genderrelated differences were observed in PCS scores. PCS scores for each of its subscales were not associated with opioid consumption.

Table 1. Descriptive Statistics of the Scores of the Total PCS Questionnaire as Well as its Three Subscales

\begin{tabular}{|c|c|c|}
\hline Score & Range & Mean \pm SD \\
\hline \hline Rumination & $0-16$ & $4.00 \pm 4.4$ \\
\hline Magnification & $0-6$ & $1.48 \pm 1.8$ \\
\hline Helplessness & $0-21$ & $4.75 \pm 5.1$ \\
\hline Total PCS & $0-41$ & $10.02 \pm 10.3$ \\
\hline
\end{tabular}

\section{Characteristics of APTP}

Fig. (1) depicts the characteristics of the four measures of the APTP scores obtained on the $2^{\text {nd }}$ and $5^{\text {th }}$ days. Two pain measures obtained during rest differed in the two time points of their assessment. Namely, higher pain intensities were reported on the $5^{\text {th }}$ postthoracotomy day compared to the $2^{\text {nd }}$ for the Rest general $(43.3 \pm 29.96$ vs. $26.4 \pm 26.5 ; P<0.0001)$ as well as Rest $_{\text {incision }}$ pain $(19.1 \pm 23.9$ vs. $10.7 \pm 17.3 ; P=0.003)$. However, no differences were observed in the scores of provoked APTP induced by hand elevation and cough between the two postthoracotomy time points of pain assessment.

Reports of general pain, incision-related pain and coughinduced pain, which were assessed on the $2^{\text {nd }}$ postthoracotomy day, were positively correlated with those reported on the $5^{\text {th }}$ postthoracotomy day Table 2 . However, no such correlation was observed in regards to Provoked $_{\text {hand }}$

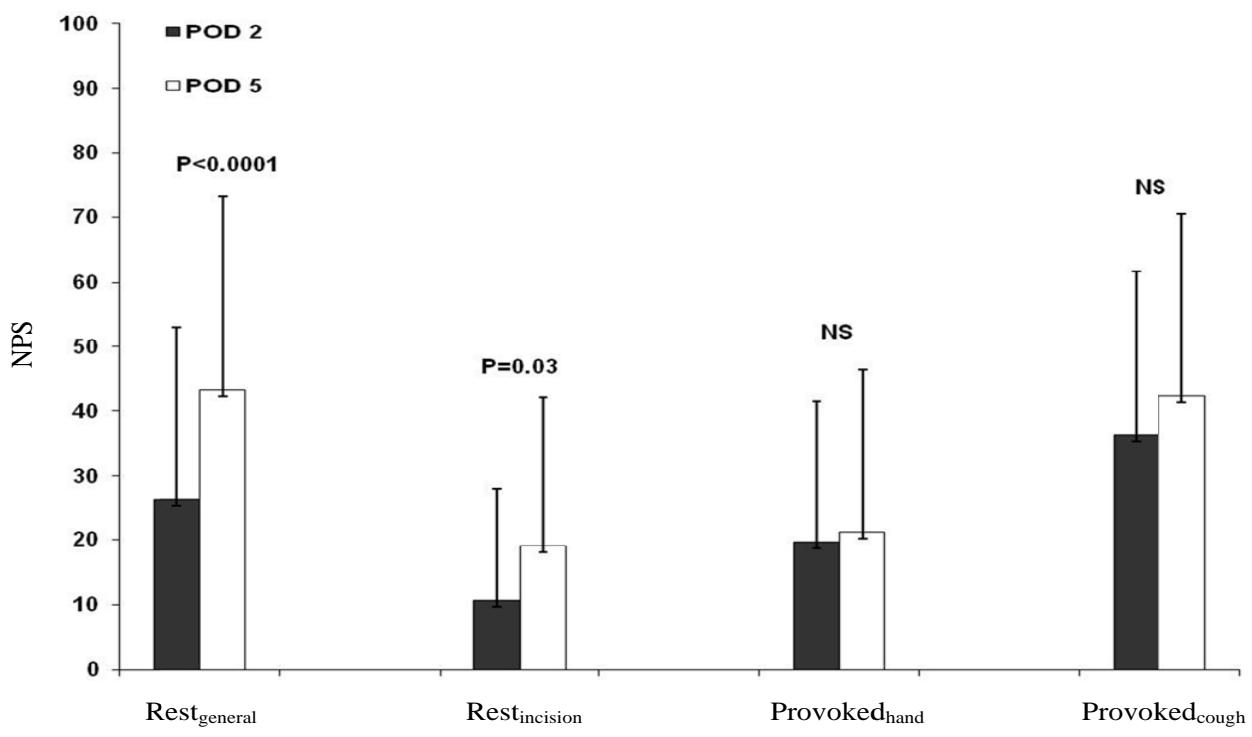

Fig. (1). The comparison between APTP scores obtained on the $2^{\text {nd }}$ and $5^{\text {th }}$ postoperative days. POD: Postoperative Day; NS: NonSignificant. 
pain. Neither rest nor provoked APTP intensities were associated with opioid consumption.

Table 2. Correlation Tests Between General Pain, IncisionRelated Pain and Cough-Induced Pain Scores Assessed on the $2^{\text {nd }}$ and $5^{\text {th }}$ Postthoracotomy Days

\begin{tabular}{|c|c|c|}
\hline Pain Rating & $\begin{array}{c}\text { Correlation } \\
\text { Coefficient }\end{array}$ & P-value \\
\hline \hline Rest $_{\text {general }}$ & 0.543 & 0.001 \\
\hline Rest $_{\text {incision }}$ & 0.370 & 0.022 \\
\hline Provoked $_{\text {hand }}$ & 0.124 & 0.466 \\
\hline Provoked $_{\text {cough }}$ & 0.410 & 0.012 \\
\hline
\end{tabular}

\section{Characteristics of CPTP}

Mean time of chronic pain follow-up was $4.5 \pm 2.3$ months. Eleven patients $(23.9 \%)$ reported of CPTP greater than 30 during the past week, and were thus defined as suffering from chronic pain; their mean pain score was $47.73 \pm 10.3$. The remaining non-CPTP 35 patients $(76.1 \%)$ reported a mean pain score of $10.57 \pm 12.1$. The mean CPTP score reported by all patients collectively was $19.46 \pm 19.8$.

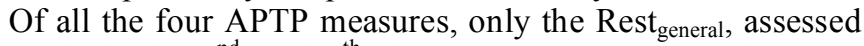
on both the $2^{\text {nd }}$ and $5^{\text {th }}$ days, was associated with CPTP scores (r=0.321, $P=0.034 ; \mathrm{r}=0.400, P=0.024$, respectively).

\section{Association Between PCS and Postthoracotomy Pain}

A comparison between CPTP and non-CPTP patients revealed significantly greater scores in all three PCS subscales for the former group (Fig. 2). All three PCS subscales were positively correlated with the CPTP scores, namely Rumination $(\mathrm{r}=0.582, P<0.0001)$, Magnification, $(\mathrm{r}=0.310, P=0.046)$ and Helplessness $(\mathrm{r}=0.453, P=0.003)$. Mediation analyses with revealed that the PCS and its subscales did not mediate the association between acute pain assessed on the $2^{\text {nd }}$ postthoracotomy day and chronic postthoracotomy pain. However, the association between acute Rest $_{\text {general }}$ pain assessed on the $5^{\text {th }}$ postthoracotomy day and chronic postthoracotomy pain was significantly mediated by general PCS scores $(P<0.001)$, rumination $(P=0.003)$, magnification, $(P=0.006)$ and helplessness scores $(P=0.001)$.

Further examining the correlations between the PCS subscales and the postthoracotomy pain paramenters revealed that of the four APTP measures, only the

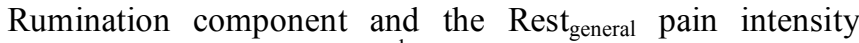
obtained during the $2^{\text {nd }}$ posthoracotomy day were significantly associated $(\mathrm{r}=0.337 ; P=0.027)$.

\section{Prediction of CPTP}

A linear rergession model was conducted to determine the relative contriburtion of pain catastrophizing to the prediction of CPTP scores. Since Rest general was associated with the rumination component of the PCS, their interaction was also included as a potential affector. Although no differences were found between males and females as to the scores of the various PCS subscales as well as postthoracotomy pain scores, gender was also included in the regression model due to the fact that females have been demonstrated to report higher pain catastrophiing scores than men $[1,5,20]$. The regression model $\left(\mathrm{R}^{2}=0.442 ; P=0.001\right)$ revealed that only the rumination subscale of the PCS significantly predicted CPTP intensity (Table $\mathbf{3}$ ).

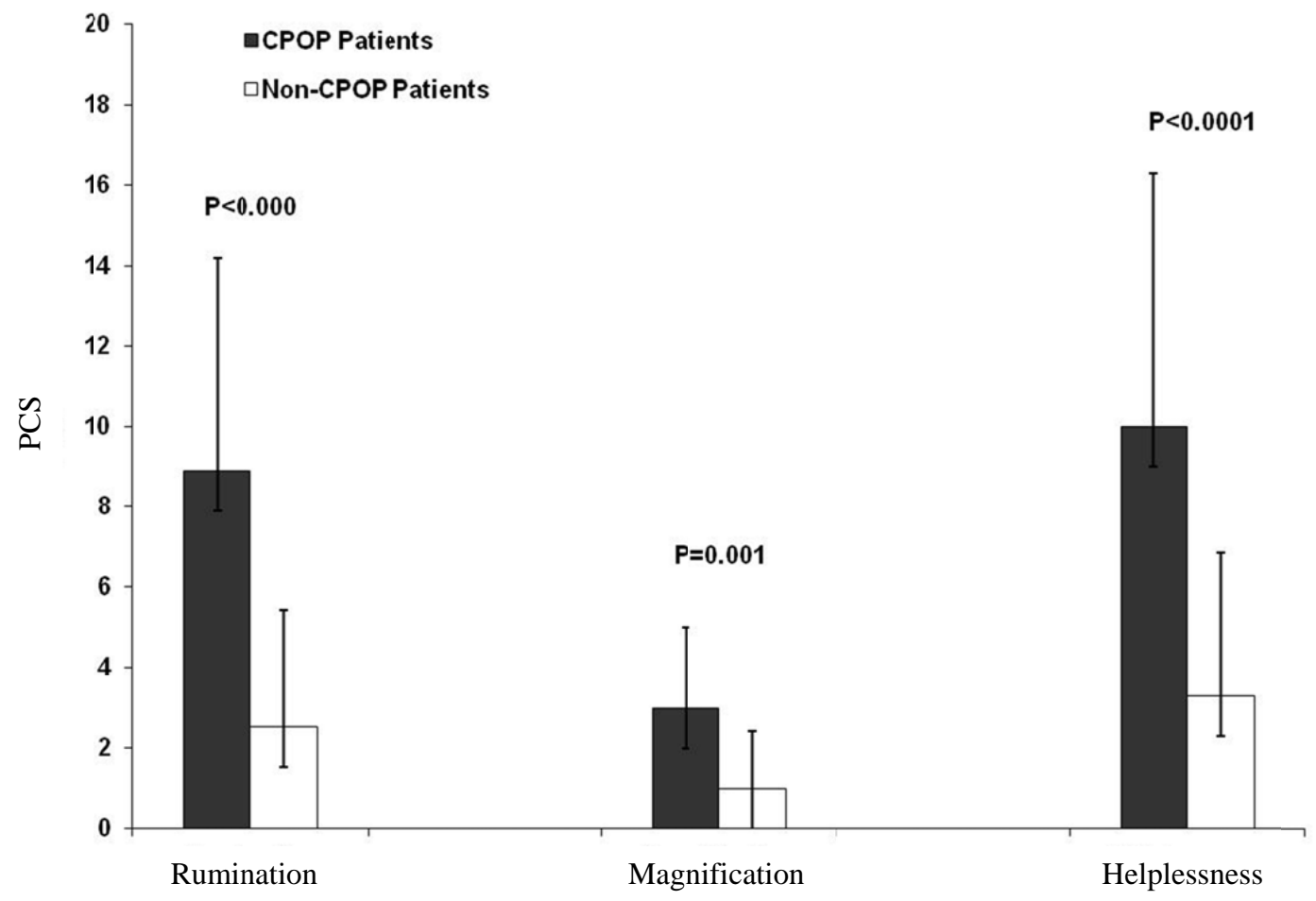

Fig. (2). A comparison between CPTP and non-CPTP patients in terms of the three PCS subscales. 
Table 3. A Linear Rergession Model for the Prediction of Chronic Postthoracotomy Pain, which Included the Three PCS Subscales and the General Pain Obtained During the $2^{\text {nd }}$ Postoperative Day. POD: Postoperative Day

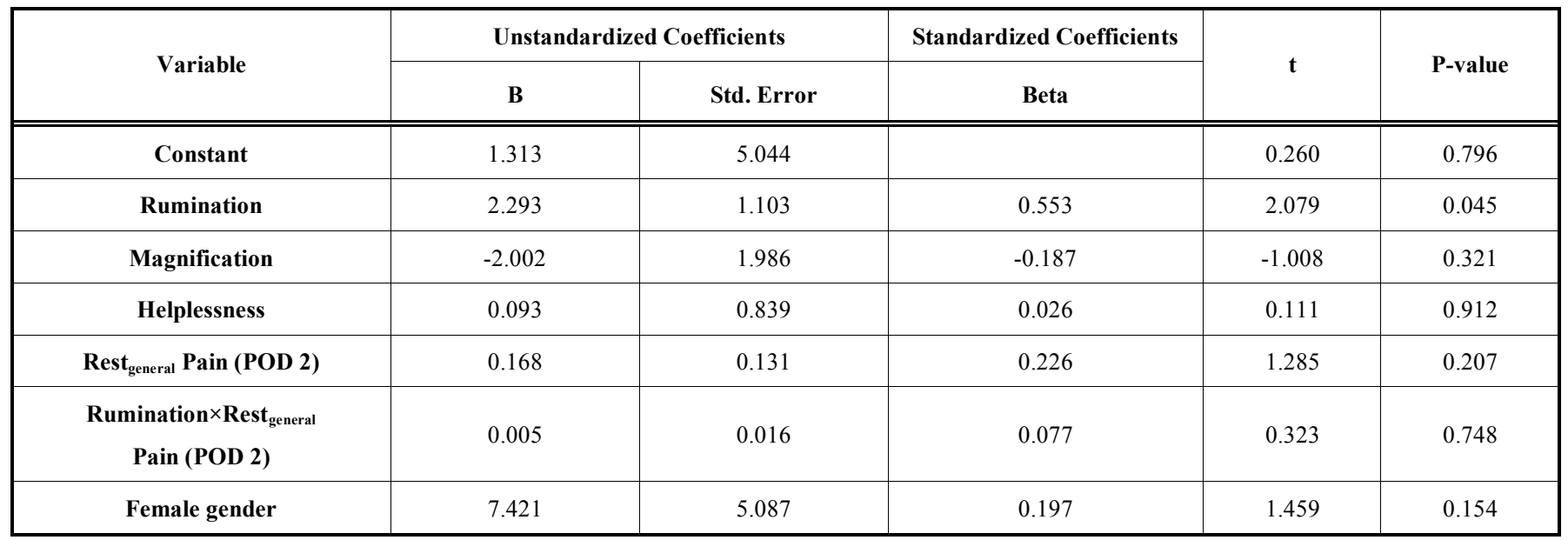

\section{DISCUSSION}

The main finding of this prospective study is that the rumination subscale of the PCS assessed presurgically in response to noxious experimental stimuli may serve as the most sensitive predictor of both acute and chronic postthoracotomy pain. This assertion is based on two observations: First, greater scores of the rumination subscale of the PCS were associated with higher general pain reports obtained at rest during the $2^{\text {nd }}$ postthoracotomy day. Second, the regression analyses revealed that only the rumination subscale scores significantly predicated the intensity of chronic postthoracotomy pain, notwithstanding that all three PCS subscales were separately correlated with its intensity. In addition, higher PCS scores were positively correlated with higher CPTP scores. Moreover, the transition from acute to chronic postthoracotomy pain was mediated by general PCS scores as well as its subscales.

Thus far, the vast majority of the studies which explored the association between pain catastrophizing and characteristics of postoperative pain utilized the total score of the PCS, which may have masked the distinctive role of each of its components. The approach of the current study was to characterize the associations between each of the PCS subscales and postoperative pain intensity.

The rumination subscale, namely the tendency to focus excessively on pain sensation [1], emerged in the current study as the most sensitive predictor of acute and chronic postthoracotomy pain. As to acute pain prediction, the current finding is in line with a report by Sullivan and Neish [21], who demonstrated that of the three PCS subscales, rumination was the only significant predictor of pain intensity following dental hygiene treatment. In another report, Sullivan et al. [22] showed that the rumination subscale was the strongest predictor of pain and disability in patients with soft-tissue injuries to the neck, shoulders or back. The rumination subscale also showed the strongest association with the severity and number of symptoms among patients with upper respiratory tract illness [23]. As for chronic pain, Forsythe et al. [24] found that rumination was the only subscale capable of discriminating between patients with and without pain at 24 months after total knee arthroplasty.

Several mechanisms may underlie these observations. First, rumination has originally been established as the predisposition to disproportionately focus on pain sensation [1]. Accordingly, it may be that subjects with higher rumination scores overly attend to pain sensations, and, therefore, amplify the experience of pain $[1,25,26]$. This concept follows the lines of previous reports, where increased attention has been closely coupled with greater individual pain experiences [26, 27]. Second, increased tendencies to focus on pain sensations, which may be reflected through greater rumination scores, were suggested to obstruct the effective utilization of pain coping strategies [28]. This may be expressed as a difficulty to control or suppress pain-related thoughts $[25,29,30]$. Third, rumination may facilitate the association between adverse emotional states and (i) perceived pain [5] as well as (ii) increased physical symptoms [23]. This notion aligns with models suggesting that anxiety states direct attention toward the feared or threatening stimulus [31], which may result in heightened clinical bodily indications. These mechanisms may explain the distinctive role of the rumination subscale in the prediction of both acute and chronic pain observed in the current study.

Nevertheless, efforts to turn attention away from pain among individuals who catastrophize failed to alleviate their pain [29]. As such, it has been suggested that patients with high PCS scores may posses a 'pain schema' that enhances the accessibility of pain-related information. This raises the question of whether the efforts are to be directed at altering catastrophizing thoughts or, alternatively, adjusting pain management to patients who demonstrate higher PCS scores, and are potentially more vulnerable to suffer from enhanced postoperative pain.

Pain ratings collected at rest during the acute postthoracotomy phase, i.e. reports of general pain and incision-related pain, differed between the $2^{\text {nd }}$ and $5^{\text {th }}$ postthoracotomy days. However, provoked pain, be it due to hand elevation or cough, was comparable in the $2^{\text {nd }}$ and $5^{\text {th }}$ postthoracotomy days. This observation may indicate that 
pain ratings collected at rest more reliably represent the postthoracotomy nociceptive processes, while pain ratings of provoked activities veil the sensations that exclusively stem from the invasive procedure. Despite these differences in general pain and incision-related pain obtained during the $2^{\text {nd }}$ vs. $5^{\text {th }}$ postthoracotomy day, current results suggest that individuals may be characterized with a unique pain responsiveness profile; this may be indicated by the correlations between these two pain score assessments.

The framework of the current study allowed us to assess the distinct role of the three PCS subscales as well as the four APTP parameters, each representing a particular facet of the immediate postoperative pain experience. Moreover, these four measures were obtained on two time points along the acute postoperative phase, which attest to the examined patient's pain experience with and without regional analgesia. This study design enabled the elucidation of the manner in which pain catastrophizing affects the manifestation of postoperative pain.

Recent literature suggests that less efficient pain modulation capacity is associated with greater risk of postoperative pain $[31,32]$. This study emphasizes the role of the cognitive aspect in determining individual postoperative pain responsiveness. Therefore, a better exploration of the association between pain modulation efficacy and cognitive processes induced by nociceptive events may advance the construction of a clinically reliable pain profile predicting augmented postoperative pain.

PCS and its subscales mediated the transition from acute pain, which was assessed on the $5^{\text {th }}$ postoperative day and not the $2^{\text {nd }}$, to chronic postoperative pain. One possible explanation may be attributed to the fact that on the $5^{\text {th }}$ day patients were not under the thoracic epidural catheter. Therefore, the pain intensity that patients experienced was not as masked by analgesics, and, accordingly, may have reflected more reliably their increased tendency for painrelated thoughts.

The main limitations of the current study are that APTP scores were assessed only twice during the patients' hospitalization, and that potentially relevant sociodemographic and personality factors were not assessed. As to the former - a more delineated individual pain profile may have yielded a more accurate analysis; as to the latter - such factors may have more specifically elucidated the individual predisposition to the development of acute and chronic pain conditions.

\section{CONCLUSION}

This study emphasizes the significance of the PCS in general, and its three subscales in particular, in the manifestation of cognitive pain processes induced by surgery. The particular role of rumination points that patients characterized by higher predisposition to focus on their pain may necessitate an adjusted clinical care in order to reduce their expected enhanced postoperative pain experiences. Moreover, current findings illuminate the particular role of pain catastrophizing thinking as a mediator between acute and chronic pain.

\section{CONFLICT OF INTEREST}

The author(s) confirm that this article content has no conflicts of interest.

\section{ACKNOWLEDGEMENT}

Declared none.

\section{REFERENCES}

[1] Sullivan MJL, Bishop SR, Pivik J. The Pain Catastrophizing Scale: development and validation. Psychol Assess 1995; 7: 524-32.

[2] McWilliams LA, Asmundson GJ. The relationship of adult attachment dimensions to pain-related fear, hypervigilance, and catastrophizing. Pain 2007; 127: 27-34.

[3] Lautenbacher S, Huber C, Baum C, Rossaint R, Hochrein S, Heesen M. Attentional avoidance of negative experiences as predictor of postoperative pain ratings and consumption of analgesics: comparison with other psychological predictors. Pain Med 2011; 12: 645-53.

[4] Martínez MP, Sánchez AI, Miró E, Medina A, Lami MJ. The relationship between the fear-avoidance model of pain and personality traits in fibromyalgia patients. J Clin Psychol Med Settings 2011; 18: 380-91

[5] Sullivan MJ, Thorn B, Haythornthwaite JA, et al. Theoretical perspectives on the relation between catastrophizing and pain. Clin J Pain 2001; 17: 52-64.

[6] Sullivan MJ, Feuerstein M, Gatchel R, Linton SJ, Pransky G. Integrating psychosocial and behavioral interventions to achieve optimal rehabilitation outcomes. J Occup Rehabil 2005; 15: 47589.

[7] Velly AM, Look JO, Carlson C, et al. The effect of catastrophizing and depression on chronic pain - a prospective cohort study of temporomandibular muscle and joint pain disorders. Pain 2011; 152: $2377-83$.

[8] Martin CE, Johnson E, Wechter ME, Leserman J, Zolnoun DA. Catastrophizing: a predictor of persistent pain among women with endometriosis at 1 year. Hum Reprod 2011; 26: 3078- 84 .

[9] Thorn BE, Pence LB, Ward LC, et al. A randomized clinical trial of targeted cognitive behavioral treatment to reduce catastrophizing in chronic headache sufferers. J Pain 2007; 8: 938-49.

[10] Lautenbacher S, Huber C, Kunz M, et al. Hypervigilance as predictor of postoperative acute pain: its predictive potency compared with experimental pain sensitivity, cortisol reactivity, and affective state. Clin J Pain 2009; 25: 92-100.

[11] Lautenbacher S, Huber C, Schöfer D, et al. Attentional and emotional mechanisms related to pain as predictors of chronic postoperative pain: a comparison with other psychological and physiological predictors. Pain 2010; 151: 722-31.

[12] Granot M, Ferber SG. The roles of pain catastrophizing and anxiety in the prediction of postoperative pain intensity: a prospective study. Clin J Pain 2005; 21: 439-45.

[13] Khan RS, Ahmed K, Blakeway E, et al. Catastrophizing: a predictive factor for postoperative pain. Am J Surg 2011; 201: 12231 .

[14] Pavlin DJ, Sullivan MJ, Freund PR, Roesen K. Catastrophizing: a risk factor for postoperative pain. Clin J Pain 2005; 21: 83-90.

[15] Roth ML, Tripp DA, Harrison MH, Sullivan M, Carson P. Demographic and psychosocial predictors of acute perioperative pain for total knee arthroplasty. Pain Res Manag 2007; 12: 185-94.

[16] Sommer M, de Rijke JM, van Kleef M, et al. Predictors of acute postoperative pain after elective surgery. Clin J Pain 2010; 26: 8794.

[17] Papaioannou M, Skapinakis P, Damigos D, Mavreas V, Broumas $\mathrm{G}$, Palgimesi A. The role of catastrophizing in the prediction of postoperative pain. Pain Med 2009; 10: 1452-59.

[18] Swinkels-Meewisse IE, Roelofs J, Oostendorp RA, Verbeek AL, Vlaeyen JW. Acute low back pain: pain-related fear and pain catastrophizing influence physical performance and perceived disability. Pain 2006; 120: 36-43.

[19] Kovacs F, Noguera J, Abraira V, et al. Spanish Back Pain Research Network. The influence of psychological factors on low back painrelated disability in community dwelling older persons. Pain Med 2008; 9: 871-80. 
[20] Hechler T, Vervoort T, Hamann M, et al. Parental catastrophizing about their child's chronic pain: are mothers and fathers different? Eur J Pain 2011; 15: 515.e1-9.

[21] Sullivan MJ, Neish NR. Catastrophizing, anxiety and pain during dental hygiene treatment. Community Dent Oral Epidemiol 1998a; 26: 344-9.

[22] Sullivan MJ, Stanish W, Waite H, Sullivan M, Tripp DA. Catastrophizing, pain, and disability in patients with soft-tissue injuries. Pain 1998b; 77: 253-60.

[23] Devoulyte K, Sullivan MJ. Pain catastrophizing and symptom severity during upper respiratory tract illness. Clin J Pain 2003; 19: 125-33.

[24] Forsythe ME, Dunbar MJ, Hennigar AW, Sullivan MJ, Gross M. Prospective relation between catastrophizing and residual pain following knee arthroplasty: two-year follow-up. Pain Res Manag 2008; 13: 335-41.

[25] Leventhal H, Brown D, Shacham S, Engquist G. The effects of preparatory information about sensations, threat of pain, and attention on cold pressor distress. J Pers Soc Psychol 1979; 37: 688-714.
[26] Fernandez E, Turk DC. The utility of cognitive coping strategies for altering pain perception: a meta-analysis. Pain 1987; 38: 12335.

[27] McCaul KD, Malott JM. Distraction and coping with pain. Psychol Bull 1984; 95: 516-33.

[28] Spanos NP, Radtke-Bodorik HL, Ferguson JD, Jones B. The effects of hypnotic susceptibility, suggestions for analgesia, and utilization of cognitive strategies on the reduction of pain. J Abnorm Psychol 1979; 88: 282-92.

[29] Heyneman NE, Fremouw WJ, Gano D, Kirkland F, Heiden L. Individual differences and the effectiveness of different coping strategies for pain. Cogn Ther Res 1990; 14: 63-77.

[30] Eccleston C, Crombez G. Pain demands attention: a cognitiveaffective model of the interruptive function of pain. Psychol Bull 1999; 125: 356-66.

[31] Weissman-Fogel I, Granovsky Y, Crispel Y, Ben-Nun A, Best LA, Yarnitsky D, Granot M. Enhanced presurgical pain temporal summation response predicts postthoracotomy pain intensity during the acute postoperative phase. J Pain 2009; 10: 628-36.

[32] Yarnitsky D, Crispel Y, Eisenberg E, et al. Prediction of chronic post-operative pain: pre-operative DNIC testing identifies patients at risk. Pain 2008; 138: 22-8.

Received: February 10, 2013

Revised: June 04, 2013

Accepted: June 20, 2013

(C) Kremer et al.; Licensee Bentham Open.

This is an open access article licensed under the terms of the Creative Commons Attribution Non-Commercial License (http://creativecommons.org/licenses/by-nc/3.0/) which permits unrestricted, non-commercial use, distribution and reproduction in any medium, provided the work is properly cited. 